\title{
Effectiveness of Teaching Program on Knowledge of Clinical Nurses Regarding Risk of Unplanned Extubation of Patients with Mechanical Ventilation at a Selected Hospital, Bangalore
}

\author{
Gulafshan $^{1}$, Umadevi A $K^{2}$ \\ ${ }^{1}$ Lecturer, Dept of Medical Surgical Nursing, Ambedkar Institute of Nursing, Rajiv Gandhi University of Health \\ Sciences, Karnataka \\ ${ }^{2}$ Prof. and HOD, Dept of Medical Surgical Nursing, Kempegowda College of Nursing, Rajiv Gandhi University \\ of Health Sciences, Karnataka \\ Corresponding Author: Umadevi A K
}

\begin{abstract}
Background: Mechanical ventilation (MV) is one of the therapeutic pillars of intensive care medicine. Technique and practice in emergency airway management varies between ICUs and in different countries and as a result, complication rates may also differ. Unplanned extubation is a frequent event after endotracheal intubation for respiratory support in critically ill patients and is associated with increased morbidity and mortality. The incidence of unplanned extubation among intubated patients is reported to vary from $0.3 \%$ to $1.4 \%$. Unplanned extubation account for approximately $10 \%$ of reintubations. An Unplanned Extubation is also associated with prolonged duration of mechanical ventilation, ICU stay and hospital stay.

Objective: to assess the knowledge of clinical nurses regarding risk of unplanned extubation of patients with mechanical ventilation at Kempegowda institute of medical science and research Hospital, Bangalore, Karnataka.

Materials and Methods: Quantitative research approach and a pre-experimental one group pretest post-test research design were used to accomplish the stated objectives. The investigator selected a sample of 50 nurses who were working in KIMS hospital. The data were collected by using a self administered structured knowledge questionnaire. Planned teaching was given with appropriate $\mathrm{A}-\mathrm{V}$ aid followed by pretest.
\end{abstract}

Result: Inferential and descriptive statistical analysis was performed by using SPSS-IBM 20. Results were calculated by using $\mathrm{p}$ value $<0.05$. The results revealed that, in pretest $80 \%$ of the nurses had inadequate knowledge where as in posttest $82 \%$ of the nurses had gained moderately adequate knowledge and the improvement was statistically significant at $\mathrm{P}<0.05$.

Conclusion: The study result shows that after intervention knowledge regarding risk of unplanned extubation among nurses were improved significantly.

Key words: Effectiveness planned teaching, risk of unplanned extubation, knowledge of staff nurses and mechanical ventilation protocol.

\section{INTRODUCTION}

"Prana, the vital breath, is born of Self. Like a person and his shadow, the Self and thePrana are inseparable. Prana enters the body at birth, but does not die with the body"

-Prana Upanishad

Oxygen $\left(\mathrm{O}_{2}\right)$ is a gas that is essential for life, as well as a potent drug used for relief of hypoxemia and hypoxia. Respiration is necessary for sustaining life of an individual ${ }^{2}$. In many disorders, the airway becomes narrowed or blocked as a result of disease, bronchoconstriction, a foreign body or secretions. Maintaining a 
patent airway in an emergency situation such as airway obstruction or in long-term management is achieved through meticulous airway management, by introducing an endotracheal or a tracheostomy tube ${ }^{3}$.

If a patient has a continuous decrease in oxygenation, an increase in arterial carbon dioxide levels and a persistent acidosis, mechanical ventilation may be necessary.

Mechanical ventilation (MV) is one of the therapeutic pillars of intensive care medicine. MV has become the most common procedure for the management of critically ill patients.

Complications can occur from pressure exerted by the cuff on the tracheal wall. High cuff pressure can cause tracheal bleeding, ischemia and pressure necrosis, whereas low cuff pressure can increase the risk of aspiration pneumonia ${ }^{3}$. Complications (which can be lifethreatening) may occur in up to $40 \%$ of critically ill patients ${ }^{5}$.

The weaning process is essential to the care of critically ill patients. It includes the process of patients weaning from MV releasing the patient from the ventilatory support and endotracheal tube ${ }^{5}$. The physician, nurse practitioner or respiratory advanced-practice nurse performs the steps in the process of weaning and extubation ${ }^{7}$.

In patients requiring mechanical ventilation, weaning failure is relatively common, with an estimated prevalence of $31 \%$ and a range of $26-42 \%$.

Unplanned extubation is a frequent event after endotracheal intubation for respiratory support in critically ill patients and is associated with increased morbidity and mortality. The incidence of unplanned extubation among intubated patients is reported to vary from $0.3 \%$ to $1.4 \%$. Unplanned extubation account for approximately $10 \%$ of reintubations. An Unplanned Extubation is also associated with prolonged duration of mechanical ventilation, ICU stay andhospital stay ${ }^{10}$.

The nurse plays an important role in helping the critically ill patient breathe. The nurse must be knowledgeable and skilled in assessing patient needs, providing quick and efficient care, evaluating results of intervention, supporting and teaching the patient and family. Techniques, equipment and procedure to support and teach the patient vary according to their respiratory status $^{8}$.

\section{Statement of the Problem}

A study to assess the effectiveness of structured teaching programme on knowledge of clinical nurses regarding risk of unplanned extubation of patients with mechanical ventilation at Kempegowda Institute of Medical Science and Research Hospital, Bangalore, Karnataka.

\section{Objectives}

1. To assess the knowledge of clinical nurses regarding risk of unplanned extubation of patients with mechanical ventilation.

2. To assess the effectiveness of planned teaching programme on knowledge of clinical nurses regarding risk of unplanned extubation of patients with mechanical ventilation.

3. To find out the association between the pre-test knowledge scores of clinical nurses with selected demographic variables.

\section{Hypotheses}

$\mathrm{H}_{1}$ : There may be significant improvement in mean post-test knowledge score compared to mean pre-test knowledge score of clinical nurses regarding risk of unplanned extubation of patients with mechanical ventilation.

$\mathrm{H}_{2}$ : There may be significant association between knowledge of clinical nurses with selected demographic variables.

\section{METHODOLOGY}

A pre-experimental one group pretest- posttest was used to accomplish the stated objectives. The investigator selected a sample of 50 clinical nurses who met the inclusion criteria using a convenient sampling technique. The research tool was developed after doing extensive literature review. The primary and secondary sources 
of literature were reviewed to develop an appropriate tool. Experts from ICU, anesthetist and nursing provided their opinion and valuable suggestions which were incorporated to develop the tool. The tool consisted of socio demographic characteristics and structured knowledge questionnaire. Structured knowledge questionnaire consisted of 40 items on knowledge regarding risk of unplanned extubation of patients with mechanical ventilation. Component-1: Consists of 19 items $(50 \%)$ introduction to unplanned extubation. Component-2: Consists of 12 items $(31.57 \%)$ risk factors and management of unplanned extubation. Component-3: consists of 9 items $(23.68 \%)$ nursing management of unplanned extubation. The total knowledge score was interpreted as score of $<50 \%$-inadequate, $51 \%-75 \%$-moderately adequate and $>76 \%$ adequate. STP was developed by referring the books and journals. It contains information regarding risk factors, signs and symptoms, treatment of unplanned extubation.

\section{Inclusion criteria}

1. Clinical nurses who were willing and present at the time of data collection

Data collection procedure: Data collection procedure includes pretest, STP and post test. The data were collected by self administered structured knowledge questionnaire during these phases of study. After obtaining the formal permission from Administrative Medical Officer and Nursing Director of Kempegowda Institute of Medical Science Hospital and Research Center the researcher approached Nursing Superintendent and the 50 clinical nurses were selected by using purposive sampling technique who met the inclusion criteria. The nurses were informed about the day and duration of pre-test. The day before pre-test, the researcher remained all the staff nurses through Nursing Director and ward in charges. The nurses were informed to gather at Radiology Seminar Hall in Ground floor in Kempegowda Institute of Medical
Science Hospital and Research Center, Bangalore. The need for the study and the objectives were explained to the staff nurses. Anonymity and confidentiality was assured and written informed consent was obtained from the samples before conducting the pre-test. The investigator informed all the samples to answer all the questions given in the questionnaire and also assured that doubts in knowledge questionnaire will be clarified during PTP. The investigator collected data from 50 nurses that took 40-45 minutes for each nurse to complete the structured knowledge questionnaire.

Ethical consideration: Prior to the data collection, participants were informed about the study and written consent was obtained from each participant. Institutional human ethical committee clearance and permission was obtained to conduct the study.

Implementation of STP: After pre-test, the PTP was administered for 50 samples for about 45 minutes by using power point. The seating arrangements were made comfortably so that all the nurses can view the power point projector. Doubts raised in between PTP were cleared then and there. All the staff nurses cooperated well and participated actively. They came forward with their queries about risk of unplanned extubation of patients with mechanical ventilation. They also showed a positive attitude in group discussion. Post-test was administered on 8th day after PTP by using the same self-administered knowledge questionnaires on risk of unplanned extubation. All the participants were cooperated well with the investigator in both pre-test and post-test sessions. The data collection process was terminated by thanking the subjects for their cooperation.

\section{RESULTS}

\section{Statistical analysis}

Statistics were performed by using SPSS-IBM 17. Results were calculated by using $\mathrm{P}$ value $<0.05$. Chi-square was used to associate the knowledge and practice scores 
with selected demographic variables. Frequency and percentage distribution was used to analyze the demographic variables.
Paired ' $t$ ' test was used to find out the effectiveness of STP.

Table 1: Frequency Distribution of Demographic Characteristics $\mathbf{N}=\mathbf{5 0}$

\begin{tabular}{|c|c|c|c|}
\hline Sl.No & Demographic Characteristics & Frequency (No.) & Percentage $(\%)$ \\
\hline \multirow[t]{3}{*}{ Age in Years } & $25-30$ & 32 & 64 \\
\hline & $31-35$ & 14 & 28 \\
\hline & Above 35 & 4 & 8 \\
\hline \multirow[t]{4}{*}{ Years of Clinical experience } & $0-5$ & 6 & 12 \\
\hline & $5-10$ & 37 & 74 \\
\hline & $10-15$ & 4 & 8 \\
\hline & $>15$ & 3 & 6 \\
\hline \multirow[t]{3}{*}{ Educational qualification } & GNM & 47 & 94 \\
\hline & B.sc nursing & 1 & 2 \\
\hline & Post B.sc nursing & 2 & 4 \\
\hline \multirow[t]{2}{*}{ Type of family } & Nuclear family & 31 & 62 \\
\hline & Joint family & 19 & 38 \\
\hline \multirow[t]{2}{*}{ Marital status } & Married & 2 & 4 \\
\hline & Single & 48 & 96 \\
\hline \multirow[t]{4}{*}{ Monthly family income } & Rs. $10,000-20,000$ & 12 & 24 \\
\hline & Rs. $20,001-30,000$ & 26 & 52 \\
\hline & Rs. $30,001-40,000$ & 9 & 18 \\
\hline & Above Rs. 40,001 & 3 & 6 \\
\hline \multirow[t]{2}{*}{ Place of residence } & Urban & 30 & 60 \\
\hline & Rural & 20 & 40 \\
\hline
\end{tabular}

Table 1 depicts majority of respondents $47(94 \%)$ were GNM graduates and most of them were $30(60 \%)$ residing in urban Bangalore.

Table 2 shows that $40(80 \%)$ of the participants had inadequate knowledge in pretest with the mean of 17.2. In posttest, 41 $(82 \%)$ of the participants had moderately adequate knowledge and nine $(18 \%)$ of the participants had adequate knowledge and the mean was 21.7. Paired' value (9) showed that STP was very effective to improve the knowledge level of the participants and the improvement was found to be significant $(\mathrm{p}<0.005)$.

Table 3 shows that posttest mean (21.7) is higher compared to pretest mean of 17.2. The paired ' $t$ ' value (9) showed that STP was very effective to improve the knowledge level of the participants and the improvement was statistically found to be significant $(\mathrm{p}<0.005)$.

Table 2: Comparison of Knowledge of Participants in Pretest and Posttest $\mathbf{N}=50$

\begin{tabular}{|c|l|c|c|c|c|}
\hline \multirow{2}{*}{ Sl. No } & Level of Knowledge & \multicolumn{2}{|c|}{ Pretest } & \multicolumn{2}{c|}{ Posttest } \\
\cline { 3 - 6 } & & Frequency(no.) & Percentage (\%) & Frequency(no.) & Percentage (\%) \\
\hline $\mathbf{1}$ & Inadequate $(<50 \%)$ & 40 & 80 & 9 & 18 \\
\hline $\mathbf{2}$ & Moderately adequate (51\%-75\%) & 10 & 6.7 & 41 & 82 \\
\hline $\mathbf{3}$ & Adequate $>75 \%$ & 0 & - & 0 & - \\
\hline
\end{tabular}

Table 3: Comparison of Mean, Standard deviation Score of Knowledge Level of Participants in Pretest and Posttest $\mathbf{N}=\mathbf{5 0}$

\begin{tabular}{|c|c|c|c|c|}
\hline Test & Mean & SD & Paired 't'value & P value \\
\hline Pretest & 17.2 & 2.7 & 9 & $<0.005^{*}$ \\
\hline posttest & 21.7 & 2.1 & & \\
\hline \multicolumn{5}{c}{ Significant at $\mathrm{P}<0.005$}
\end{tabular}

Table 4: Aspect wise Knowledge scores of Respondents in Pre and Post tests

\begin{tabular}{|l|c|c|c|c|c|c|c|c|}
\hline \multirow{2}{*}{ Aspect wise } & \multicolumn{2}{|c|}{ Pre test } & \multicolumn{2}{c|}{ Post test } & t value & DF & P value Inference \\
\cline { 2 - 7 } & Mean & SD & Mean & SD & & & \\
\hline Introduction to unplanned extubation & 9.7 & 2 & 12.2 & 1.7 & 6.7 & 49 & $\mathrm{P}<0.005^{*}$ \\
\hline Risk factors and complications & 3.3 & 1 & 4.3 & 1.1 & 4.5 & 49 & $\mathrm{P}<0.005^{*}$ \\
\hline Nursing management & 4 & 1.6 & 5.2 & 1.5 & 3.6 & 49 & $\mathrm{P}<0.005^{*}$ \\
\hline
\end{tabular}

\section{Association with the level of knowledge of patients and their selected demographic variables}

Among the demographic variables analyzed in this study chi square value $\left(\mathrm{x}^{2}\right)$ and $\mathrm{P}$ value showed that except for the 
clinical experience there was no association found between mean pre-test score and the demographic characteristics such as age in years, gender, educational qualification, income per month, type of family, marital status, religion and place of residence.

The statistical value supported the research hypothesis that the mean posttest knowledge of risk of unplanned extubation will be significantly higher than the mean pretest knowledge score of nurses who had STP.

Thus it shows that STP was effective in improving the nurses' knowledge. This type of educational programs helps the nurses more knowledgeable and skilled in assessing patients needs, providing quick and efficient care, evaluating the results of an intervention, supporting and teaching the patient and their family.

\section{DISCUSSION}

Description of demographic variables of patients undergoing cataract surgery

The demographic variables of the nurses included in this study were age, educational qualification, years of experience, marital status, monthly family income, type of family and place of residence.

The first objective was to assess the pre and post-test knowledge of clinical nurses regarding risk of unplanned extubation of patients with mechanical ventilation.

From table 2 the study findings revealed that $40(80 \%)$ of the participants had inadequate knowledge in pretest. It indicated that the nurses need to be educated and updated to take care of a patient with mechanical ventilation. After structured teaching programme, 41 (82\%) of the nurses had moderately adequate knowledge and nine $(18 \%)$ of them had adequate knowledge and the improvement was statistically significant at $\mathrm{P}<0.005$.

The second objective was to assess the effectiveness of structured teaching programme among clinical nurses regarding risk of unplanned extubation of patients with mechanical ventilation.

In pretest the mean knowledge score obtained by the participants was 17.2 with SD of 2.7, whereas in post test the knowledge was improved to 21.7 with the SD of 2.1 which was statistically significant at $\mathrm{P}<0.005$.

The third objective was to find out the association between the pre-test knowledge scores of clinical nurses with selected demographic variables.

In this study significant association was found between clinical experience and knowledge of clinical nurses.

The present study findings confirm that there was a considerable improvement of knowledge of staff nurses on risk of unplanned extubation after PTP. In post-test $82 \%$ of staff nurses had scored up to $75 \%$ and $18 \%$ of them had scored above $50 \%$. The present study findings are supported by a similar study was conducted to evaluate the effectiveness of structured teaching programme on knowledge regarding prevention of ventilator associated pneumonia among the critical care nurses at King Khalid University; Hospital KSA revealed that, $50 \%$ of staff nurses scored above $75 \%$ compared to pre-test where $75 \%$ of them scored below $50 \%{ }^{28}$.

\section{Limitation Of The Study}

$>$ The study is limited to staff nurses of Rangadore Memorial Hospital Bangalore and Kempegowda Institute of Medical Sciences Hospital and Research Center, Bangalore.

$>$ The study did not use control group.

$>$ Only single domain i.e., knowledge was assessed in the present study.

$>$ The sample size for the study was limited to 50 staff nurses. Hence the results of the study cannot be generalized.

\section{RECOMMONDATIONS}

Based on the present study findings it is recommended that; 
$>$ On the basis of findings of the present study the following recommendations havebeen made.

$>$ A replication of present study can be conducted with a large sample.

$>$ A similar study can be conducted in different settings with a control group and randomization.

$>$ A comparative study can be conducted between nurses working in government and private hospital settings.

$>$ Manuals and information booklets may be developed to enhance knowledge of staff nurses regarding risk of unplanned extubation of patients with mechanical ventilation.

$>$ A study can be conducted by including additional demographic variables such as knowledge of complications and management of unplanned extubation of patients with mechanical ventilation.

$>$ The same study can be conducted on other domains such as attitude and practice.

$>$ A follow-up study of planned teaching programme can be carried out to find the effectiveness in terms of retention of knowledge.

$>$ A similar study can be conducted among nurses and other health care personnel.

$>$ The same study can be conducted as comparative study between patients in different departments.

$>$ A same study can be conducted with the use of video assisted teaching on risk of unplanned extubation of patients with mechanical ventilation.

\section{CONCLUSION}

Nurses contribute significantly to the care of patients with respiratory problems by taking a comprehensive history and performing a thorough physical examination. This information allows the nurse to establish a baseline level of assessment of patient's status andprovides a frame work for detection of rapid changes in the patient's condition. Assessments are valuable if made before, during and after interventions that are likely to alter or improve respiratory status. Because the nurse is with the patient more consistently than other health care professionals, it is often the nurse who detects the patient's changing condition. High quality assessments often uncover complications or changes that precede the information provided by other diagnostic tests

\section{Acknowledgement: None}

\section{Conflict of Interest: None}

\section{Source of Funding: None}

\section{Ethical Approval: Approved}

\section{REFERENCES}

1. Potter \& Perry, Text Book of fundamentals of nursing $6^{\text {th }}$ edition. Elsevier Australia.2008 P-91.

2. Donna D Ignatavicius. Text Book of Medical-Surgical Nursing Patient Centered Collaborative Care. $8^{\text {th }}$ ed. Elsevier Saunders 2006. P- 542.

3. Brunner \& Suddhartha. Text Book of Medical-Surgical Nursing. $12^{\text {th }}$ ed. New Delhi; Wolters - kluwer (india) pvt Ltd; I;487, 562-565.

4. Anup Das, Prathyush P, Menon, Jonathan G. Optimization of mehanical ventilator settings for pulmonary disease states. Iee transactions of biomedical engineering. 60(6); 2013.

5. Maria Lucia Gimenez, Gabriel Alejandro Verde, Iris Gloria Salvati. Characteristics of patients weaning from mechanical ventilation, a multicenter study. Ramr.2; 2016, p113- 119.

6. G.D.Simpson, M.J.Ross, D.W.Mckeown and D.C.Ray. Tracheal intubation in the critically ill: a multi-center national study of practice and complications. British journal of Anaesthesia108 (5); 2012, p792-9.

7. Higginson R. The role of the nurse in mechanical ventilation. British journal of nurse. 20 (21);2011, p 1341.

8. Patrica Gonce Morton, Dorrie K. Fontaine critical Care Nursing: A Holistic Approach $10^{\text {th }}$ Edition. LWW; North American edition p568, 2012. 
9. Bokes M J, Marsh B. Weaning from mechanical ventilation. I(5);2007, p103356.

10. M Sesmu Arbous, Evert de Jonge, Ingeborg HF Herold, Olaf M Dekkers, Robin I de Groot. Risk factors and outcomes after unplanned extubations on ICU: a casecontrol study. Critical care. 15(1):2015.

11. Lea Fialkow, Mauricio Farenzena, Luri Christmann Wawrzeniak, Janete Salles Brauner, Sílvia Regina Rios Vieira, Alvaro Vigoand Mary Clarisse Bozzetti. Mechanical ventilation in patients in the intensive care unit of a general university Hospital in southern Brazil: an epidemiological study. Clinics (online). 71 (3);2016, p144-151.

12. Tobi KU, Ekwere IT and Ochukpe C. Mechanical ventilation in the intensive care unit: A prospective study of indications and factors that affect outcome in a Tertiary Hospital in Nigeria. J Anesth Clin Res. 8(4); 2017.

13. Tae Won Lee, Jeong Woo Hong, Jung-Wan Yoo, Unplanned Extubation in Patients with Mechanical Ventilation: Experience in the Medical Intensive Care Unit of a Single Tertiary Hospital. Tuberculosis Respiratory Diseases (Seoul). 78 (4); 2015, 336-340.

14. Paulo Sergio Lucas da Silva and Marcelo Cunio Machado Fonseca, Unplanned Endotracheal Extubations in the Intensive Care Unit: Systematic Review, Critical Appraisal, and Evidence-Based Recommendations. 114:(5) 2012.

15. Weir S, O Neill A. Experiences of intensive care nurses assessing sedation/agitation in critically ill patients. 13(4); 2008,p 185-94.

16. Bhanu Paramjyothi B, Limi Elsa Daniel and Dr. Indira S. A study to assess the knowledge regarding ET suctioning among staff nurses and student nurses in $\mathrm{NMCH}$, Nellore. IJAR 2(6);2016, 150-152.

17. AK Alotaibi, SK Alotaibi, M Alshayiqi, S Ramalingam. Knowledge and attitudes of Saudi intensive care unit nurses regarding oral care delivery to mechanically ventilated patients with the effect of healthcare quality accreditation. 10; 2016, p 208-212.

18. NilimaBhore. A descriptive study to assess the nurses' knowledge about nosocomial infection. IJNH.1 (4); 2015, p 229-235.

19. Diptisorte. Nurses Knowledge related to prevention of nosocomial infection.
Internationaljournal of scientific research. 4 (7); 2015, 30-40.

20. Raghda Elbokhary, Await Osama, Mugahed Al-Khader. Knowledge and practice of ICU nurse regarding endotracheal suctioning of mechanically ventilated patients in Khartoum Teaching Hospital, Sudan. American journal of clinical neurology and neurosurgery. 1(2);2015, p92-98.

21. SimoneCidade Lima Ribeir' Eliane Regina Pereira do Nasciment. Knowledge of nurses about delirium in critical patients: collective subject discourse.24 (2); 2015.

22. Jose Melquiades RamalhoNeto, Lusia Balbino does Nascimento. Accidental extubation and intensive care nursing. $\mathbf{J}$ Nurs UFPE on line.8 (11); 2014, 3945-52. .

23. Sasmita Das, rashmi mala Pradhan, Twinkil Patel. An intergrated review of nurses knowledge on therapeutic and diagnostic equipment with a view to develop guidelines. International Journal of Recent Scientific Research 5 (6); 2014, p1 161.

24. Fathima thsuhara k, Jancy George, Jancy thomas k. Assessment of knowledge regarding mechanical ventilation among staff nurses working in selected Hospital, Mangalore with a view to develop an information pamphlet. International Journal of Recent Scientific Research 4(9); 013, 1410-1413.

25. Oleci Pereira Frota, Marisa Dias Rolan Loureiro. Knowledge about endotracheal suctioning on the part of intensive care nursing professionals: a descriptive study. Online Brazilian Journal of Nursing. 12 (2); 2013, 546-54.

26. AKAlotaibi, SK Alotaibi, M Alshayiqi. Knowledge and attitudes of Saudi intensive care unit nurses regarding oral care delivery to mechanically ventilated patients with the effect of health care quality accredidation. 10; 2015, p208-212.

27. Sunil Maurya, Shakti B Mishra, Afzal Azim. Ventilator- associated complications: A study to evaluate the effectiveness of a planned teaching program for intensive care unit staff nurses- an Indian experience. American Jounal of infection control. 1(11); 2016, 1422-1423.

28. Rajini, Vasantha kalyani. Assess the effectiveness of structured teaching program on level of knowledge regarding infection control practices among staff nurses working in critical care units. International 
Gulafshan et.al. Effectiveness of teaching program on knowledge of clinical nurses regarding risk of unplanned extubation of patients with mechanical ventilation at a selected hospital, Bangalore

Journal of Recent Scientific Research. 7; 2016, p12593-12598.

29. Tulsi Shringi. Assessing the effectiveness of planned teaching program on knowledge regarding the care of patient on ventilator among staff nurses in intensive care unit. Health Care: Current Reviews.3:3; 2015. New Delhi, India
How to cite this article: Gulafshan, Umadevi A K. Effectiveness of teaching program on knowledge of clinical nurses regarding risk of unplanned extubation of patients with mechanical ventilation at a selected hospital, Bangalore. International Journal of Science \& Healthcare Research. 2021; 6(3): 452-459. DOI: https://doi.org/10.52403/ijshr.20210773 